\title{
Calculation of the width of cracks in class 3 prestressed beams
}

\author{
E. W. BENNETT \& C. S. CHANDRASEKHAR
}

Dr N. Krishna Raju and Mr U. C. Ahamed Kutty, Karnataka Regional Engineering College, University of Mysore, India

The Authors are to be congratulated for suggesting a simple method for calculation of crack width in class 3 type prestressed beams.

31. The mechanism of crack formation is such that a wide scatter is inherent in the measured values of crack widths in tests. In a recent investigation involving tests on class 3 type pretensioned prestressed beams in our laboratory, we have noted variations of up to $50 \%$ from the mean in the measured values of crack widths and a similar observation has been made by Hognestad. ${ }^{15}$

32. It is widely accepted that important parameters controlling the width of cracks are the stress in steel, diameter of bar, type of reinforcement, cover and effective reinforcement ratio.

33. The CEB-FIP proposals significantly underestimate the crack widths for non-repetitive loads, because many controlling parameters are not considered in their recommendations.

34. Since the diameter of reinforcement is an important parameter controlling crack width, it is necessary to use the same diameter of reinforcement to study the influence of the type of reinforcement on load-crack width relationship. In this respect, Fig. 5 does not represent a true picture of the relation between the variables intended to be studied by the Authors.

35. Investigations by Kaar and Mattock ${ }^{16}$ show that, for a given steel stress, there is an apparent correlation between crack width and the area of concrete surrounding each bar regardless of bar diameter. Their tests have revealed that the best crack control is obtained when the reinforcing bars are well distributed over the effective concrete area surrounding the bars and having the same centroid as the total reinforcement, in the case of girders with T-, I- and rectangular section.

36. In a recent series of tests on class 3 type pretensioned beams with mild steel as untensioned reinforcement, we have found that the maximum crack width can be ascertained by an expression of the type:

$$
w=\frac{k}{p_{\mathrm{e}}} \cdot c \cdot f_{\mathrm{ot}}
$$

where, $c$ is the cover over reinforcement

$f_{\text {ct }}$ is the fictitious tensile stress in concrete

$p_{e}$ is the percentage of untensioned reinforcement and

$k$ is a factor depending on the type of reinforcement.

The experimental value of $k$ is $750 \times 10^{-\theta} \mathrm{mm}^{2} / \mathrm{N}$ for mild steel bars of $10 \mathrm{~mm}$ diameter having a guaranteed yield stress of $300 \mathrm{~N} / \mathrm{m}^{2}$. The percentage of untensioned reinforcement varied from 0.5 to 1.5 .

37. It would be interesting to study the magnitude of standard deviation and coefficient of variation of the ratio of calculated to measured crack widths in the range from 30 to $55 \%$ of the ultimate load. Can we assume that it is of the same order as that presented in Table 3 ?

Paper published: Proc. Instn Civ. Engrs, 1971, 49 (July) 333-346. 
to take some of the uncertainty out of the industry and to cut down on waste and provide more security. He might also form Ministries of Planning and of Traffic.

Mr P. Trench advocated a construction academy, a super-body to represent the building industry. The President of the RIBA, Mr A. Gordon, who was a delegate to the Conference, spoke of the Presidents' Committee for the Urban Environment which had recently been formed to act rather as a Senior Liaison Organization. This was greeted with considerable enthusiasm as one of the most encouraging developments in the industry; it was felt that it was a significant step towards the construction academy. Mr Trench also put forward an idea for a national agency to deal with slum clearance, having greater powers than local authorities and consequently not vote-conscious. He said that the building industry could cope adequately with the rehousing of slum dwellers if only the local authorities would make the money and land available. Sir Hubert Bennett, on the other hand, thought that the promotion of charities and housing associations to help buy their homes would result in the disappearance of slums, and incidentally of vandalism. Sir Hubert also spoke of the need to build several new towns free from the limitations of Building Regulations and cost limits.

Mr R. Macleod, Director of the Institute of Advanced Architectural Studies at York, summing up, spoke of his Institute's courses, which encouraged total design. $\mathrm{He}$ had also worked as a project manager in Canada and declared that the superefficiency of the idea did not exist-one operated 'by the seat of one's pants'. He redefined professionalism and emphasized that the motivations of professionals and contractors would have to be changed before they could be expected to change their roles.

Another point which came in for universal criticism was the traditional method of competitive tendering. It was agreed by all sides (with the exception of the Department of the Environment) that the present system was one of the major contributory causes of the lack of progress and inefficiency in the industry; a move to forms of negotiated contract was stongly advocated, although it was admitted by $\mathrm{Mr}$ Trench that many contractors were their own worst enemies in adopting a short-sighted attitude when given the chance to negotiate, by attempting to make 'a killing'.

The Conference, which was considered a success, agreed that we could not afford a building industry without a conscience, and it was hoped that many of the points which were raised would be followed up, possibly in Presidents' Committee for the Urban Environment.

The Conference was closed by the Chairman, who briefly restated the aims and functions of the organization, and thanked all the speakers. 